\title{
Preparation of Polypropylene Powder by Dissolution-Precipitation Method for Selective Laser Sintering
}

\author{
Liang Fang $(\mathbb{D}$, Yan Wang $(\mathbb{D}$, and Yang Xu \\ School of Material Science and Engineering, Wuhan Institute of Technology, Wuhan 430074, Hubei, China \\ Correspondence should be addressed to Yan Wang; wangyan@wit.edu.cn
}

Received 18 April 2019; Accepted 1 July 2019; Published 14 July 2019

Guest Editor: Chunze Yan

Copyright (C) 2019 Liang Fang et al. This is an open access article distributed under the Creative Commons Attribution License, which permits unrestricted use, distribution, and reproduction in any medium, provided the original work is properly cited.

\begin{abstract}
Polypropylene (PP) powder with spherical morphology and suitable particle size for selective laser sintering (SLS) was successfully produced by dissolution-precipitation method. The influence of preparation condition on properties of PP powder was investigated. The experimental results show that the optimal preparation conditions are as follows: dissolution temperature being about $166^{\circ} \mathrm{C}$, pressure being about $0.7 \mathrm{MPa}$, and the solid-to-solvent ratio being about $0.067 \mathrm{~g} / \mathrm{ml}$. The prepared PP powder displayed a narrow size distribution with the mean size of about $42.7 \mu \mathrm{m}$ and the apparent density of powder about $0.40 \mathrm{~g} / \mathrm{cm}^{3}$. The specimens produced by laser sintering of the PP powder showed smooth appearance and good dimensional accuracy. The tensile strength and impact strength of the sintered parts were $27.9 \mathrm{MPa}$ and $6.3 \mathrm{KJ} / \mathrm{m}^{2}$, respectively, which are basically equal to the properties of the injection molded parts.
\end{abstract}

\section{Introduction}

Selective laser sintering (SLS) is a widespread additive manufacturing technology and a three-dimensional object which is created layer by layer from heat-fusible powdered materials with heat supplied from a moving laser beam [1-4]. Compared with other additive manufacturing technologies, one of the main advantages associated with SLS is material versatility. Compared with metal materials and ceramic materials, the polymer material requires less energy during sintering, so that a relatively low energy laser beam can be used to sinter the polymer material. This permits lower laser energy to be employed by SLS than required for directly sintering with metals and ceramics. Although in theory any polymer available in powder form can be processed by laser sintering, only a few polymer powders can be used for manufacturing parts with high mechanical properties, surface quality, and accuracy [5-9]. According to viscous sintering mechanism, it is difficult to produce fully dense SLS parts from amorphous polymers because of the high viscosity above glass transition temperature. For crystalline polymers, the part bed temperature can be kept near melt point that fully dense parts can be produced because the powders under the laser heating can be melted completely $[10,11]$.
In SLS process, amorphous polymers like polycarbonate (PC) and polystyrene (PS) have been used to create models, patterns, and parts for investment casting applications, while crystalline polymers, like polyamide, have been used to produce functional parts which have fully dense and good mechanical properties. Polyamide 12 (PA12) is certainly the most widely used laser sintering materials at the present time [12-16]. However, since the price of PA12 powder is very expensive, which limits its further promotion in SLS, it is of great significance to develop polymer powder with low cost but excellent performance [17].

$\mathrm{PP}$ is the most common semicrystalline polymer extensively applied in many fields due to its low cost and good material performance such as a relatively low density, superior mechanical properties, high temperature resistance, corrosion resistance, good electrical properties, and chemical stability [18-20]. The aim of this paper is to investigate the production of laser sintering PP powders with appropriate particle size and spherical morphology.

Generally, the preparation of PP powder includes cryogenic milling and dissolution-precipitation method. Cryogenic milling mainly uses ceramic or metallic balls or blades to break bulk PP resin at a low temperature below $-50^{\circ} \mathrm{C}$ and 
TABLE 1: The effects of MFR of PP on preparation of powders.

\begin{tabular}{lcc}
\hline Grades & Melt index $(\mathrm{g} / 10 \mathrm{~min})$ & Experimental result \\
\hline T30S & 6.0 & Sol, hardly possible to separation \\
SA233CF & 8.1 & Sol, hardly possible to separation \\
RP707CF & 8.9 & Small block \\
SD233CF & 10.0 & Small block \\
K3500 & 11.1 & Powdery, difficult in separation \\
HJ730 & 17.8 & Powdery, easy to separation \\
eps30r & 34.0 & Powdery, easy to separation \\
\hline
\end{tabular}

then prepare it into powder [21]. But PP powders produced by cryogenic milling show poor powder flowability, unfavorable particle morphology, and inappropriate particle size distributions [22]. This paper uses dissolution-precipitation to produce PP powders. Dissolving PP in a suitable solvent at a high temperature, and then by changing the temperature or adding second kinds of non-solvent, PP will precipitate as powders $[23,24]$. By controlling suitable process conditions, nearly spherical PP particles with appropriate particle size could be prepared.

\section{Materials and Methods}

2.1. Materials. PP resin (grades: SK3500, SD233CF, RP707CF, SA233CF, HJ730, T30S, and eps30r) was used for the experiment. The solvent was xylene (containing $99.0 \%$ xylene, $0.1 \%$ benzene, and $0.1 \%$ methylbenzene), which was obtained from Tianjin Fuyu Fine Chemical Co., Ltd. (Tianjin, China).

2.2. Preparation of the Powders. The dissolution-precipitation procedure for the PP powders was as follows: PP resin and solvent were added to a $1 \mathrm{~L}$ high-pressure reactor. Nitrogen was added to the reactor to replace oxygen and kept the pressures in the range of $0 \sim 1.1 \mathrm{MPa}$. The mixture was stirred and heated when the temperature reached $155^{\circ} \mathrm{C} \sim 185^{\circ} \mathrm{C}$. Then, stirring was stopped and the mixture was cooled at the rate of $0.5^{\circ} \mathrm{C} / \mathrm{min}$ to $120^{\circ} \mathrm{C}$ while $\mathrm{PP}$ began to precipitate. The temperature was maintained at $120^{\circ} \mathrm{C}$ until the precipitation was completed (within $30 \mathrm{~min}$ ), and then the temperature was cooled to room temperature, the products were removed, and the solvent was filtered.

2.3. Sintering Process of the Powder. The sintering experiments of PP powder were carried out using a HK P320 laser sintering system developed by Wuhan HuaKe threedimensional Science and Technology Co., Ltd. (Wuhan, China). The sintering parameters were as follows: preheating temperature was $150^{\circ} \mathrm{C}$, the laser scanning speed was $4000 \mathrm{~mm} / \mathrm{s}$, the laser power was $22 \mathrm{~W}$, and layer thickness was $0.12 \mathrm{~mm}$.

2.4. Characterization Methods. The melt flow rate (MFR) of different grades of PP was determined with a FR-1811A MFR meter (Shanghai, China) at $230^{\circ} \mathrm{C}$ under load of $2.16 \mathrm{Kg}$. The apparent density of PP powders was tested with a XBM-100 apparent density analyzer (Chengde, China), according to the
GB/T 1636-2008 and GB/1636 standards. The size distribution and mean diameter of the powders were measured with a Winner-2000 laser particle analyzer (Jinan, China), according to the GB/T 19077.1-2008 standards. The morphologies of the powders were imaged by SEM (JSM-5510LV, Japan). The powders were coated with gold before SEM characterization to prevent charging.

The thermal behavior of PP powder was studied by differential scanning calorimetry (DSC) using a Netzsch 200F3 DSC (Erich NETZSCH GmbH \& Co., Germany). The heating rate was $10.0^{\circ} \mathrm{C} / \mathrm{min}$ from room temperature to $220^{\circ} \mathrm{C}$; then, cooling was performed at the same rate under the protection of nitrogen. The decomposition behavior was studied with a Netzsch 209F3 thermogravimeter (Erich NETZSCH GmbH \& Co., Germany). The heating rate was $20.0^{\circ} \mathrm{C} / \mathrm{min}$ from room temperature to $500^{\circ} \mathrm{C}$ under the protection of nitrogen.

The flexural properties of laser-sintered parts were measured on a WDW-50 electron universal testing machine (Shenzhen, China) using a 3-point bending test method at a test speed of $2 \mathrm{~mm} / \mathrm{min}$. Tensile tests were carried out using a WDW-50 electron universal testing machine with a crosshead speed of $50 \mathrm{~mm} / \mathrm{min}$. Izod impact tests were carried out on a XJU-22 cantilever arm impact testing machine (Chengde, China) using notched samples.

\section{Result and Discussion}

3.1. The Effects of MFR of PP on the Preparation of Powders. In order to study the influence of MFR of PP on preparation of powder, different grades of PP were chosen to prepare powder.

As shown in Table 1, the PP of the grades T30S, SA233CF, RP707CF, and SD233CF cannot be prepared into powders by dissolution-precipitation, and the obtained product is a sol or a small piece. PP of the grade K3500 can be prepared into powders, but the product must be extracted by ethanol. The addition of ethanol not only increases the production cost, but also affects the xylene (as a solvent) recycled. The PP of the grades HJ730 and eps30r can be prepared into powders, and the product is easy to be solid-liquid separated. The experimental results showed that the precipitated product of PP with a relatively low MFR is in the form of a sol or agglomerate. PP with larger MFR is easy to prepare powders. This is because the lower the MFR, the larger the relative molecular weight, and the more obvious the agglomeration between the PP powder particles, so it is easier to form a 


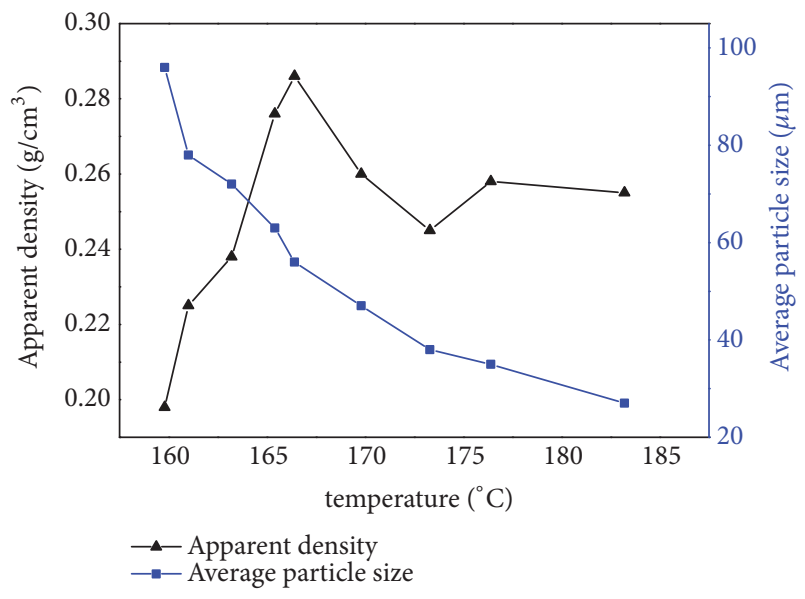

FIGURE 1: Plots of average particle size diameter and apparent density of PP powders with dissolution temperature.

gel or a block. However, the larger the MFR, the smaller the relative molecular weight of $\mathrm{PP}$, which results in the poorer performance of the sintered part prepared from the PP powder. Therefore, HJ730 with a MFR of $17.8 \mathrm{~g} /(10 \mathrm{~min})$ was selected as the raw material for preparing the PP powder.

\subsection{The Effects of Processing Parameters on the Characteristics of PP Powders}

3.2.1. Dissolution Temperature. Preparation of PP powder with dissolution-precipitation is essentially the process of dissolving PP at high temperature and precipitating at low temperature. Therefore, temperature controlling plays an important role in the preparation of PP powder.

The effects of dissolution temperature on the characteristics of powder were shown in Figure 1. As the temperature increases from $160^{\circ} \mathrm{C}$ to $185^{\circ} \mathrm{C}$, the apparent density of the powder increases firstly, then decreases, and becomes towards stability at last. The average particle size of the powder decreases with the increase of temperature. When the dissolution temperature is $166^{\circ} \mathrm{C}$, the apparent density of the powder reaches the maximum value. At lower dissolution temperature, PP particles partially dissolved, so the average particle size of powder is large; at higher temperature, the PP particles dissolved completely; the average particle size is small, only at a suitable temperature, most of the PP dissolved, and the remaining undissolved portion acts as a nucleating agent in the crystallization process, so the distribution of average particle size of prepared powder will be suitable and the apparent density of the powder will be relatively large.

3.2.2. Solid-to-Solvent Ratio. The effects of solid-to-solvent ratio on the characteristics of powder were shown in Figure 2. As the solid-to-solvent ratio increases from $0.33 \mathrm{~g} / \mathrm{ml}$ to $0.83 \mathrm{~g} / \mathrm{ml}$, the apparent density of the powder increases at first and then decreases; the average particle size of the powder dramatically increases. When the solid-to-solvent ratio is $0.067 \mathrm{~g} / \mathrm{ml}$, the apparent density of the powder is $0.37 \mathrm{~g} / \mathrm{cm} 3$ and the average particle size is $65 \mu \mathrm{m}$. The average particle size

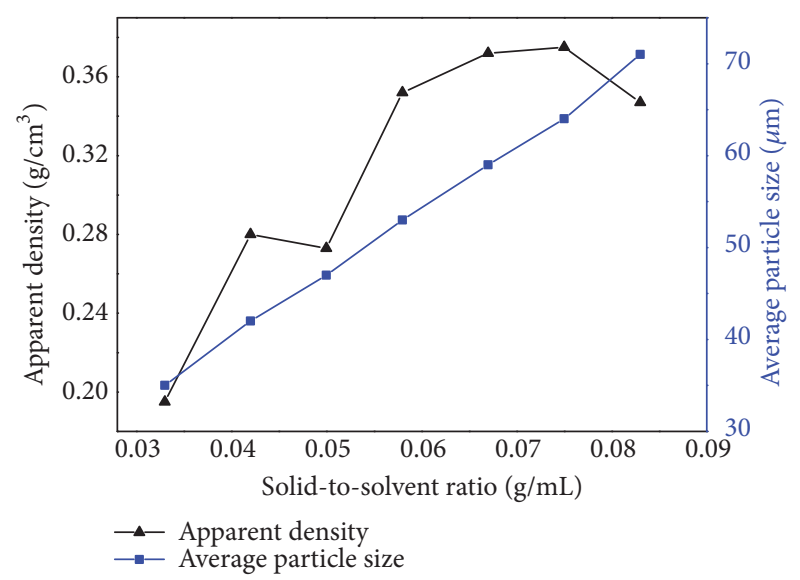

FIgURE 2: Plots of average particle size diameter and apparent density of PP powders versus solid-to-solvent ratio (dissolution temperature $166^{\circ} \mathrm{C}$ ).

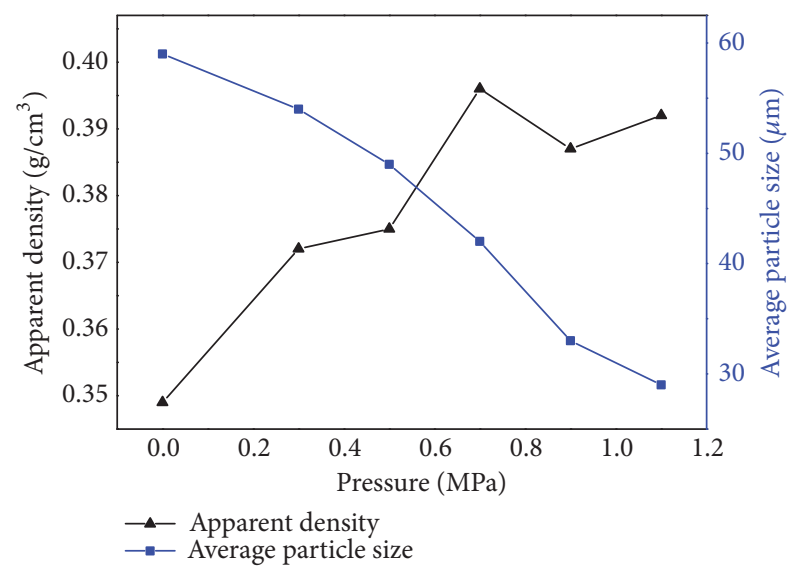

FIGURE 3: Plots of average particle size diameter and apparent density of PP powders versus pressure (dissolution temperature $166^{\circ} \mathrm{C}$, solid-to-solvent ratio $0.067 \mathrm{~g} / \mathrm{ml}$ ).

of the prepared powder decreases with the decrease of solidto-solvent ratio, but the amount of xylene in the unit mass of the preparation powder is increased, which will increase the production cost.

3.2.3. Pressure. The effects of pressure on the characteristics of powder were shown in Figure 3. During the process of gradually increasing the pressure from $0 \mathrm{MPa}$ to $1.1 \mathrm{MPa}$, the apparent density of the PP powder will gradually increase and then tend to be stable, but the particle size will gradually decrease. When the pressure is $0.7 \mathrm{MPa}$, the apparent density of the powder is $0.40 \mathrm{~g} / \mathrm{cm}^{3}$ and the average particle size is $42 \mu \mathrm{m}$. As shown in Figures 5(e) and 5(f), the surface morphology of prepared powder was very smooth and spherically good, which is consistent with the requirement of SLS for powder materials. In previous studies, a particle diameter of $20 \sim 60 \mu \mathrm{m}$ was found to be ideal for SLS.

Figure 4 shows the particle diameter distribution curves of PP powders prepared on different conditions. According 


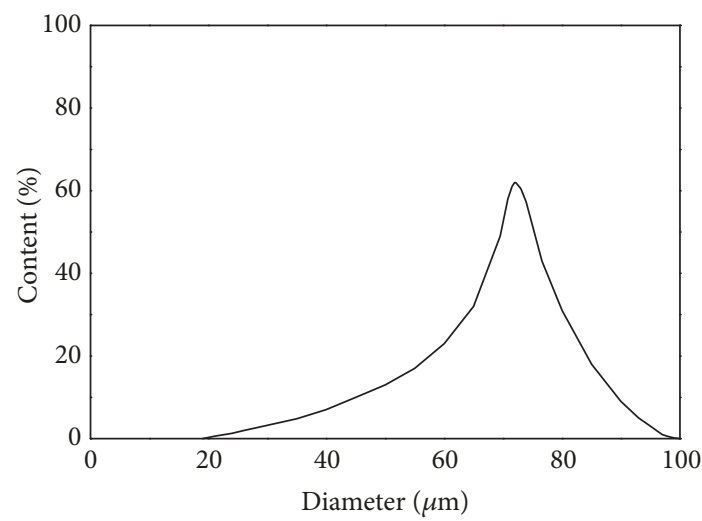

(a)

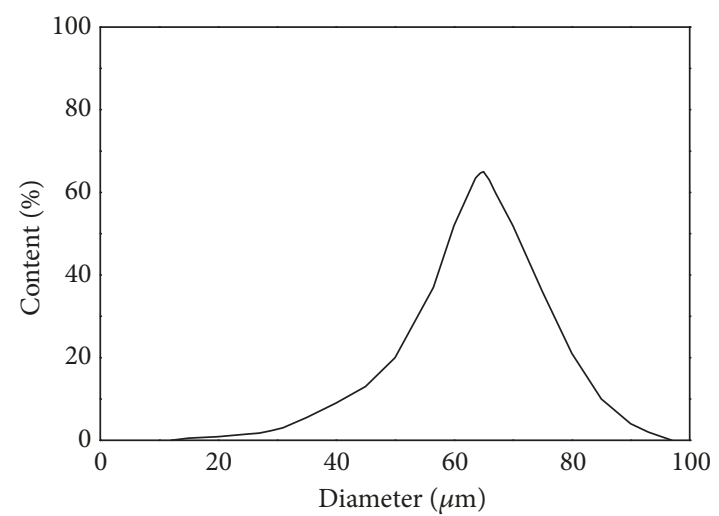

(b)

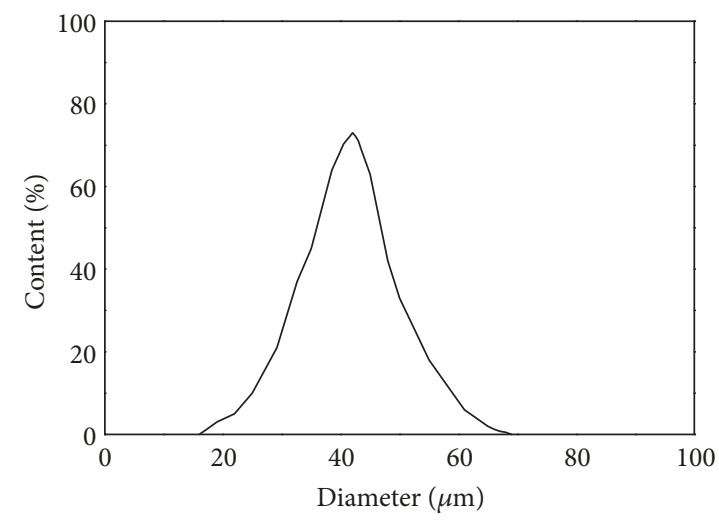

(c)

Figure 4: Particle diameter distribution curves of PP powders prepared on different conditions: (a) dissolution temperature $166^{\circ} \mathrm{C}$; (b) dissolution temperature $166^{\circ} \mathrm{C}$ and solid-to-solvent ratio $0.067 \mathrm{~g} / \mathrm{ml}$; (c) dissolution temperature $166^{\circ} \mathrm{C}$, solid-to-solvent ratio $0.067 \mathrm{~g} / \mathrm{ml}$, and pressure $0.7 \mathrm{MPa}$.

to Figure 4(a), the average diameter of the powders prepared on $166^{\circ} \mathrm{C}$ is $72 \mu \mathrm{m}$, and the distribution is wide. The powder particle size distribution curve prepared at a dissolution temperature of $166^{\circ} \mathrm{C}$ and a solid-to-solvent ratio of $0.067 \mathrm{ml} / \mathrm{g}$ are shown in Figure 4(b). The average diameter of the powder is $65 \mu \mathrm{m}$. The powders are prepared on $166^{\circ} \mathrm{C}$, the solid-tosolvent ratio is $0.067 \mathrm{~g} / \mathrm{ml}$, and the pressure is $0.7 \mathrm{MPa}$ that exhibited a narrow particle diameter distribution, as shown in Figure 4(c), with an average particle diameter of $42 \mu \mathrm{m}$.

SEM images of powders prepared on different conditions are shown in Figure 5. According to the comparison of (a), (c), (e) and (b), (d), (f), we can know that the preparation conditions have great influence on the morphology of the powders. By changing the conditions, the particle size becomes smaller, the distribution becomes narrow, and the surface turns into being smoother.

3.3. Thermal Properties of the PP Powder. DSC measurements are performed to study the thermal behavior of PP powders. The result of the DSC test for the PP powders is illustrated in Figure 6. In an analysis of the heating curve, we can observe that there is one peak; PP powder begins to melt from $177.1^{\circ} \mathrm{C}$ and ends at $185.9^{\circ} \mathrm{C}$; the melting point was $182.3^{\circ} \mathrm{C}$. By observing the cooling curve, we can find that the PP powder started to crystallize at $151.3^{\circ} \mathrm{C}$ and ended at $157.6^{\circ} \mathrm{C}$, and the crystallization temperature was $154.5^{\circ} \mathrm{C}$.

Theoretically, the SLS preheating temperature of the crystalline polymer is the temperature range at which the powder begins to melt and the melt begins to crystallize, so the theoretical preheating temperature window can be calculated using the following equation:

$$
\Delta \mathrm{T}_{0}=\mathrm{T}_{\mathrm{im}}-\mathrm{T}_{\mathrm{ic}}
$$

where $T_{i m}$ is the start temperature of melting and $T_{i c}$ is the start temperature of crystallization.

From the analysis of DSC result, we can know that the available sintering window of the PP powders is from 157.6 to $177.1^{\circ} \mathrm{C}$, and it is large enough for SLS.

Figure 7 shows the thermogravimetry (TG) curves of the PP powders. The initial degradation temperature was $323.4^{\circ} \mathrm{C}$. The decomposition temperature for 20 percent weight loss of the powder is $389.8^{\circ} \mathrm{C}$ and the $99.26 \%$ mass loss for the powder at $459.2^{\circ} \mathrm{C}$.

3.4. Selective Laser Sintering of the PP Powder. PP powder was sintered using a HK P320 laser sintering system whose performance parameters are shown in Table 2. The technological parameters during SLS are shown in Table 3. 


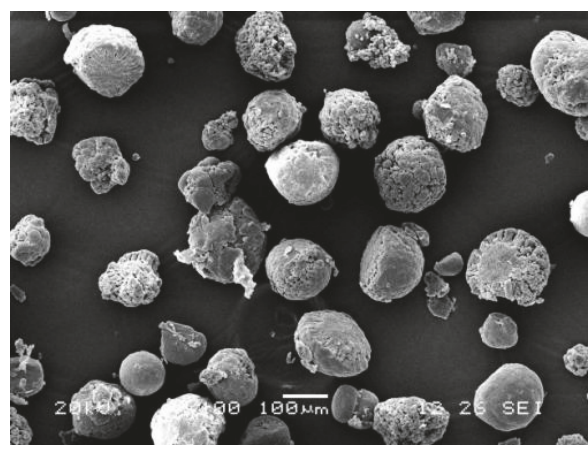

(a)

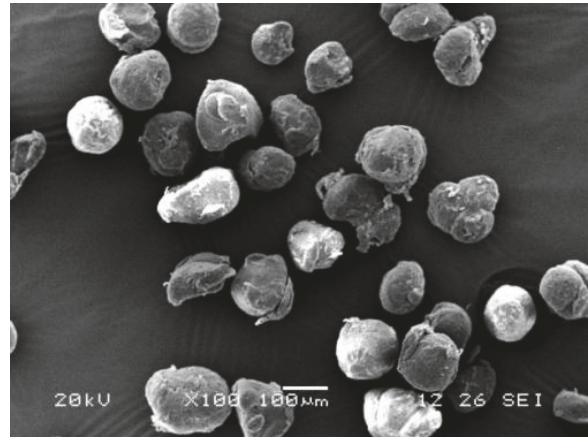

(c)

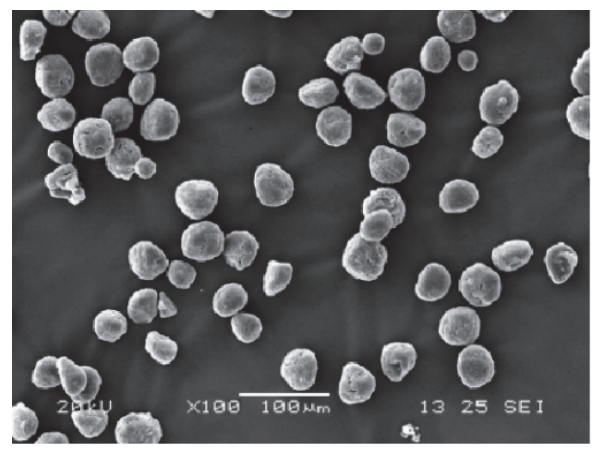

(e)

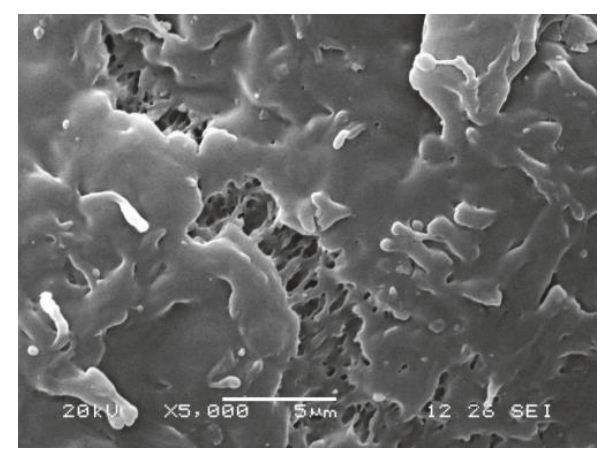

(b)

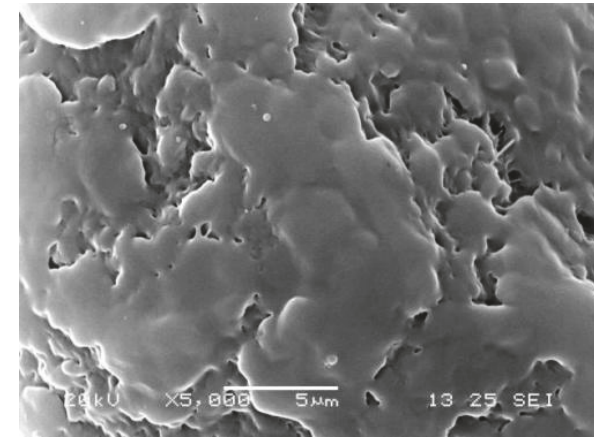

(d)

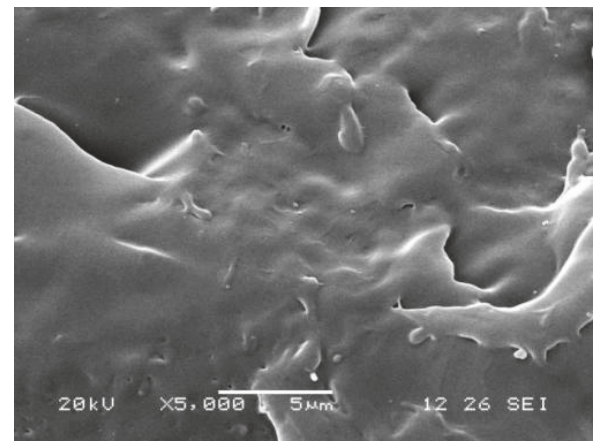

(f)

FIGURE 5: SEM graphs of PP powders prepared on different conditions: (a), (b) dissolution temperature $166^{\circ} \mathrm{C}$; (c), (d) dissolution temperature $166^{\circ} \mathrm{C}$ and solid-to-solvent ratio $0.067 \mathrm{~g} / \mathrm{ml}$; (e), (f) dissolution temperature $166.0^{\circ} \mathrm{C}$, solid-to-solvent ratio $0.067 \mathrm{~g} / \mathrm{ml}$, and pressure $0.7 \mathrm{MPa}$.

TABLE 2: Performance parameters of HK P320 laser sintering system.

\begin{tabular}{lc}
\hline Fittings of a machine & Performance parameters \\
\hline Laser & $\mathrm{CO}_{2}, 30 \mathrm{~W}$ \\
Scanning system & F-theta lens, high speed vibrating mirror, $4 \mathrm{~m} / \mathrm{s}$ \\
Layer thickness & $0.08-0.2 \mathrm{~mm}$ \\
Accuracy & $\pm 0.2 \mathrm{~mm}$ \\
SLS chamber size & $320 \mathrm{~mm} \times 320 \mathrm{~mm} \times 650 \mathrm{~mm}$ \\
Powder laying method & Automatic powder delivery, two-way powder laying \\
Forming material & Polymer powders such as PS, PP, PA6, and PA12 \\
Control software & HUST 3DP \\
Mainframe size & $1950 \mathrm{~mm} \times 1150 \mathrm{~mm} \times 2350 \mathrm{~mm}$ \\
\hline
\end{tabular}




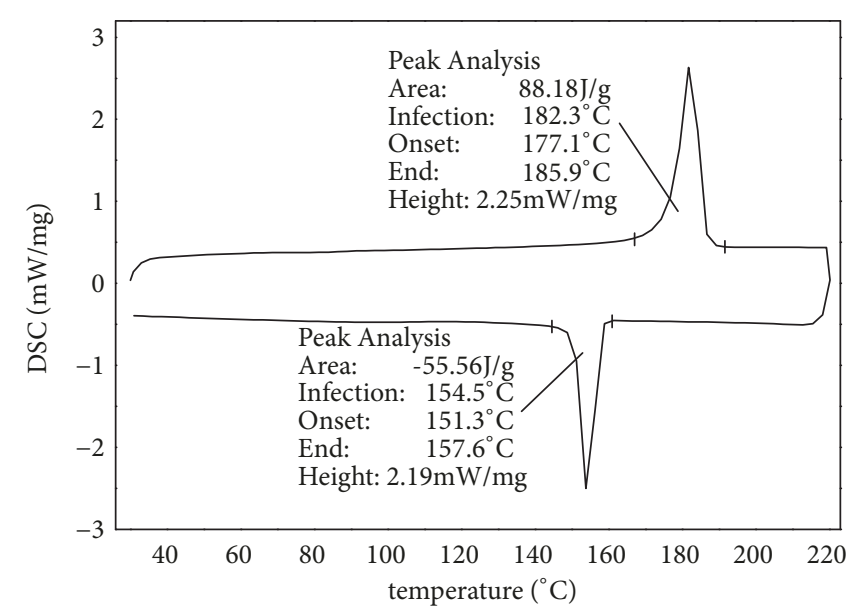

FIGURE 6: DSC result of PP powders.

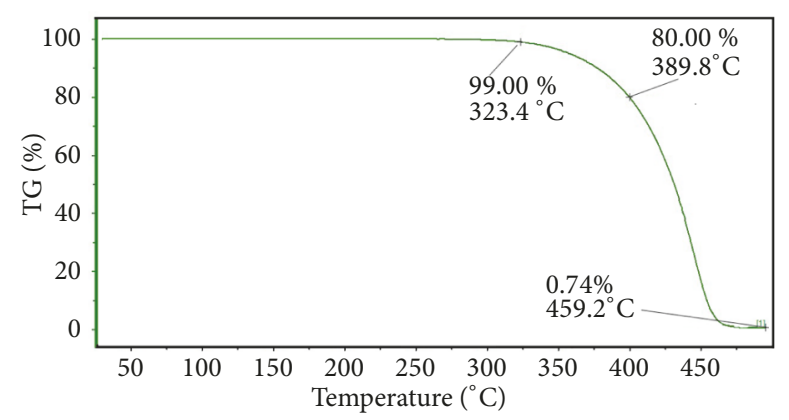

Figure 7: TG curves of PP powders.

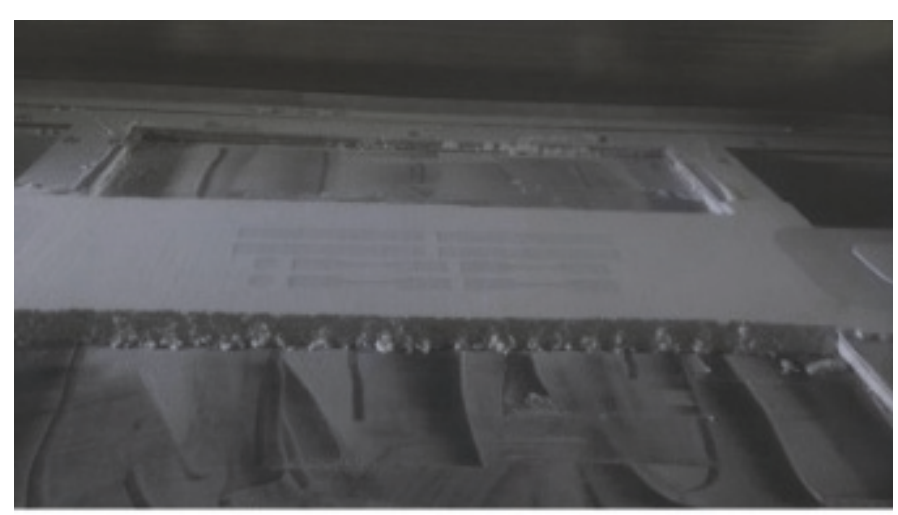

FIGURE 8: Sintering chamber.

Figure 8 shows the specific situation of the sintered parts during SLS process. The sintering parts did not warp and the powder could be reused because it did not agglomerate. Figure 9 shows that the sintered parts have good appearance quality, smooth surface, clear contour, and no warping deformation.

The mechanical properties of the sintered parts are compared with the injection parts, and the results are shown in Table 4. The tensile strength and impact strength of the sintered parts are similar to those of the injection parts, indicating that the density of the sintered parts is close to $100 \%$.

Figure 10 shows the microscopic shape of the section of samples from tensile test and impact test. The PP powder melts to form an internal dense sample which makes the mechanical properties of the sintered part close to the injected part. 


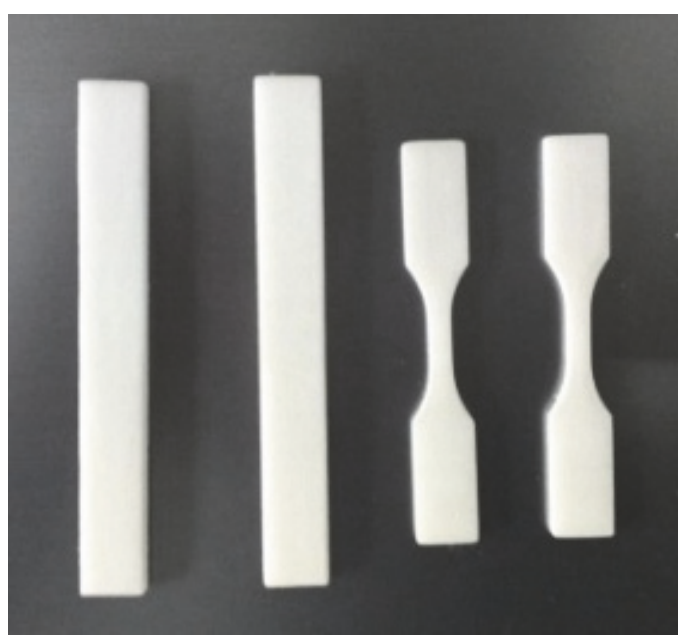

FIGURE 9: Sintering samples.

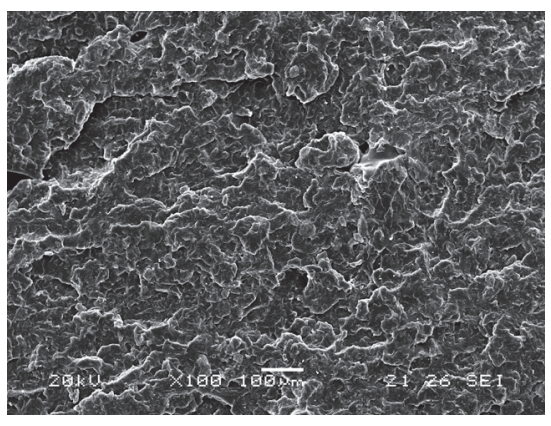

(a)

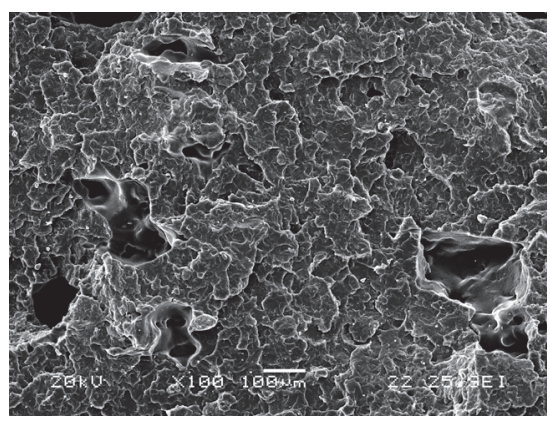

(d)

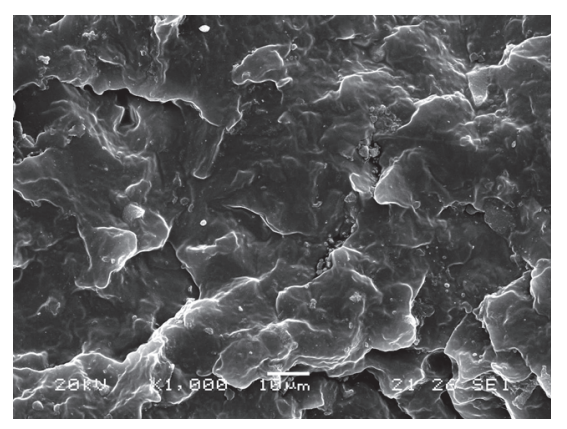

(b)

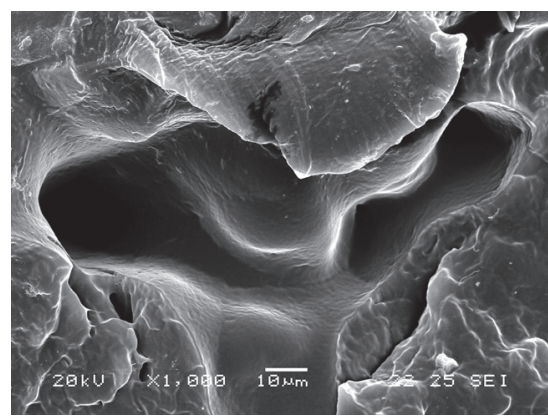

(e)

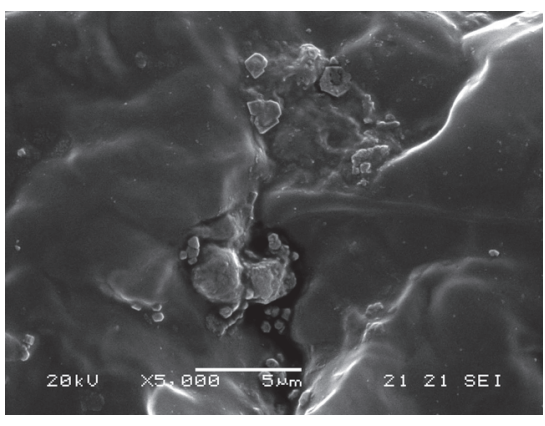

(c)

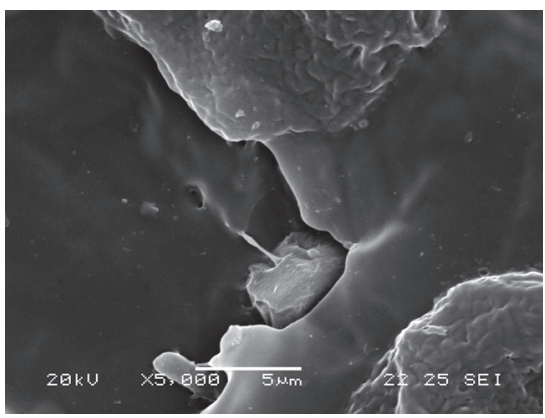

(f)

FIGURE 10: The SEM picture of the tensile test section and impact test section. (a), (b), (c): tensile test section; (d), (e), (f): impact test section.

TABLE 3: Technological parameter during SLS.

\begin{tabular}{lccc}
\hline $\begin{array}{l}\text { Preheating temperature } \\
\left({ }^{\circ} \mathrm{C}\right)\end{array}$ & $\begin{array}{c}\text { Powder layer thickness } \\
(\mathrm{mm})\end{array}$ & $\begin{array}{c}\text { Laser power } \\
(\mathrm{W})\end{array}$ & $\begin{array}{c}\text { Laser scanning speed } \\
(\mathrm{mm} / \mathrm{s})\end{array}$ \\
\hline 150 & 0.12 & 20 & 4000 \\
\hline
\end{tabular}

TABLE 4: Comparison of mechanical properties between sintering parts and injection parts.

\begin{tabular}{lcc}
\hline Mechanical property & Sintering part & Injection part \\
\hline Tensile strength $(\mathrm{MPa})$ & 27.9 & 28.7 \\
Impact strength $\left(\mathrm{KJ} / \mathrm{m}^{2}\right)$ & 6.3 & 6.5 \\
\hline
\end{tabular}




\section{Conclusions}

The study was performed to investigate the dissolutionprecipitation method for producing PP powder for SLS, and the following conclusions can be drawn from this work.

(i) PP with larger MFR is easy to prepare powders by dissolution-precipitation method. If the MFR of PP is lower than $10 \mathrm{~g} /(10 \mathrm{~min})$, it is difficult to form powder by this method.

(ii) The preparation conditions such as dissolution temperature, solid-to-solvent ratio, and pressure have important influence on the particle size and microscopic shape of powders. The average particle size of the powder decreases with the increase of temperature and pressure and the decrease of solid-to-solvent ratio.

(iii) The prepared PP powder was suitable for SLS. The sintered parts have good appearance quality, smooth surface, clear contour, and no warping deformation. The mechanical properties of sintered parts are close to those of injection parts.

\section{Data Availability}

The data used to support the findings of this study are available from the corresponding author upon request.

\section{Conflicts of Interest}

The authors declare that they have no conflicts of interest.

\section{References}

[1] W. Zhu, C. Yan, Y. Shi, S. Wen, J. Liu, and Y. Shi, "Investigation into mechanical and microstructural properties of polypropylene manufactured by selective laser sintering in comparison with injection molding counterparts," Materials and Corrosion, vol. 82, pp. 37-45, 2015.

[2] C. Yan, L. Hao, L. Xu, and Y. Shi, "Preparation, characterisation and processing of carbon fibre/polyamide-12 composites for selective laser sintering," Composites Science and Technology, vol. 71, no. 16, pp. 1834-1841, 2011.

[3] J. Yang, Y. Shi, and C. Yan, "Selective laser sintering of polyamide 12/potassium titanium whisker composites," Journal of Applied Polymer Science, vol. 117, no. 4, pp. 2196-2204, 2010.

[4] S. F. S. Shirazi, S. Gharehkhani, M. Mehrali et al., "A review on powder-based additive manufacturing for tissue engineering: selective laser sintering and inkjet 3D printing," Science and Technology of Advanced Materials, pp. 1-20, 2015.

[5] B. Wendel, D. Rietzel, F. Kühnlein, R. Feulner, G. Hülder, and E. Schmachtenberg, "Additive processing of polymers," Macromolecular Materials and Engineering, vol. 293, no. 10, pp. 799-809, 2008.

[6] M. A. Beard, O. R. Ghita, and K. E. Evans, "Monitoring the effects of selective laser sintering (SLS) build parameters on polyamide using near infrared spectroscopy," Journal of Applied Polymer Science, vol. 121, no. 6, pp. 3153-3158, 2011.

[7] D. Drummer, D. Rietzel, and F. Kühnlein, "Development of a characterization approach for the sintering behavior of new thermoplastics for selective laser sintering," Physics Procedia, vol. 5, no. 5, pp. 533-542, 2010.

[8] S. Eshraghi and S. Das, "Mechanical and microstructural properties of polycaprolactone scaffolds with one-dimensional, two-dimensional, and three-dimensional orthogonally oriented porous architectures produced by selective laser sintering," Acta Biomaterialia, vol. 6, no. 7, pp. 2467-2476, 2010.

[9] M. Vaezi, H. Seitz, and S. Yang, "A review on 3D microadditive manufacturing technologies," The International Journal of Advanced Manufacturing Technology, vol. 67, no. 5-8, pp. 1721$1754,2013$.

[10] J. Kruth, S. Kumar, and J. Van Vaerenbergh, "Study of laser-sinterability of ferro-based powders," Rapid Prototyping Journal, vol. 11, no. 5, pp. 287-292, 2005.

[11] A. Sachdeva, S. Singh, and V. S. Sharma, "Investigating surface roughness of parts produced by SLS process," The International Journal of Advanced Manufacturing Technology, vol. 64, no. 9-12, pp. 1505-1516, 2013.

[12] R. D. Goodridge, C. J. Tuck, and R. J. M. Hague, "Laser sintering of polyamides and other polymers," Progress in Materials Science, vol. 57, no. 2, pp. 229-267, 2012.

[13] W. Zhu, C. Yan, Y. Shi et al., "A novel method based on selective laser sintering for preparing high-performance carbon fibres/polyamide12/epoxy ternary composites," Scientific Reports, vol. 6, no. 1, Article ID 33780, 2016.

[14] P. Chen, M. Tang, W. Zhu et al., "Systematical mechanism of Polyamide-12 aging and its micro-structural evolution during laser sintering," Polymer Testing, vol. 67, pp. 370-379, 2018.

[15] Z. Li, W. Zhou, L. Yang et al., "Glass fiber-reinforced phenol formaldehyde resin-based electrical insulating composites fabricated by selective laser sintering," Polymer, vol. 11, no. 1, p. 135, 2019.

[16] P. Chen, H. Wu, W. Zhu et al., "Investigation into the processability, recyclability and crystalline structure of selective laser sintered polyamide 6 in comparison with polyamide 12," Polymer Testing, vol. 69, pp. 366-374, 2018.

[17] Y. Kojima, T. Matsuoka, and H. Takahashi, "Preparation of nylon 66/mesoporous molecular sieve composite under high pressure," Journal of Applied Polymer Science, vol. 74, no. 13, pp. 3254-3258, 1999.

[18] F. Rault, E. Pleyber, C. Campagne et al., "Effect of manganese nanoparticles on the mechanical, thermal and fire properties of polypropylene multifilament yarn," Polymer Degradation and Stability, vol. 94, no. 6, pp. 955-964, 2009.

[19] R. R. Hegde and G. S. Bhat, "Nanoparticle effects on structure and properties of polypropylene meltblown webs," Journal of Applied Polymer Science, vol. 115, no. 2, pp. 1062-1072, 2010.

[20] S. Yuan, F. Shen, C. K. Chua, and K. Zhou, "Polymeric composites for powder-based additive manufacturing: materials and applications," Progress in Polymer Science, vol. 91, pp. 141-168, 2019.

[21] J. Chu, C. Xiang, H. Sue et al., "Scratch resistance of mineral-filled polypropylene materials," Polymer Engineering \& Science, vol. 38, no. 11, pp. 1906-1914, 2000.

[22] W. Zhu, C. Yan, Y. Shi et al., "Study on the selective laser sintering of a low-isotacticity polypropylene powder," Rapid Prototyping Journal, vol. 22, no. 4, pp. 621-629, 2016.

[23] Y. Kojima, T. Matsuoka, and H. Takahashi, "Preparation of nylon 66/mesoporous molecular sieve composite under high pressure," Journal of Applied Polymer Science, vol. 74, no. 13, pp. 3254-3258, 2015. 
[24] J. Huang and D. Rodrigue, "The effect of carbon nanotube orientation and content on the mechanical properties of polypropylene based composites," Materials and Corrosion, vol. 55, no. 6, pp. 653-663, 2014. 


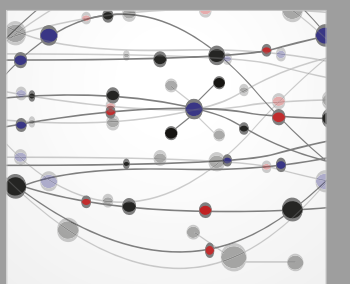

The Scientific World Journal
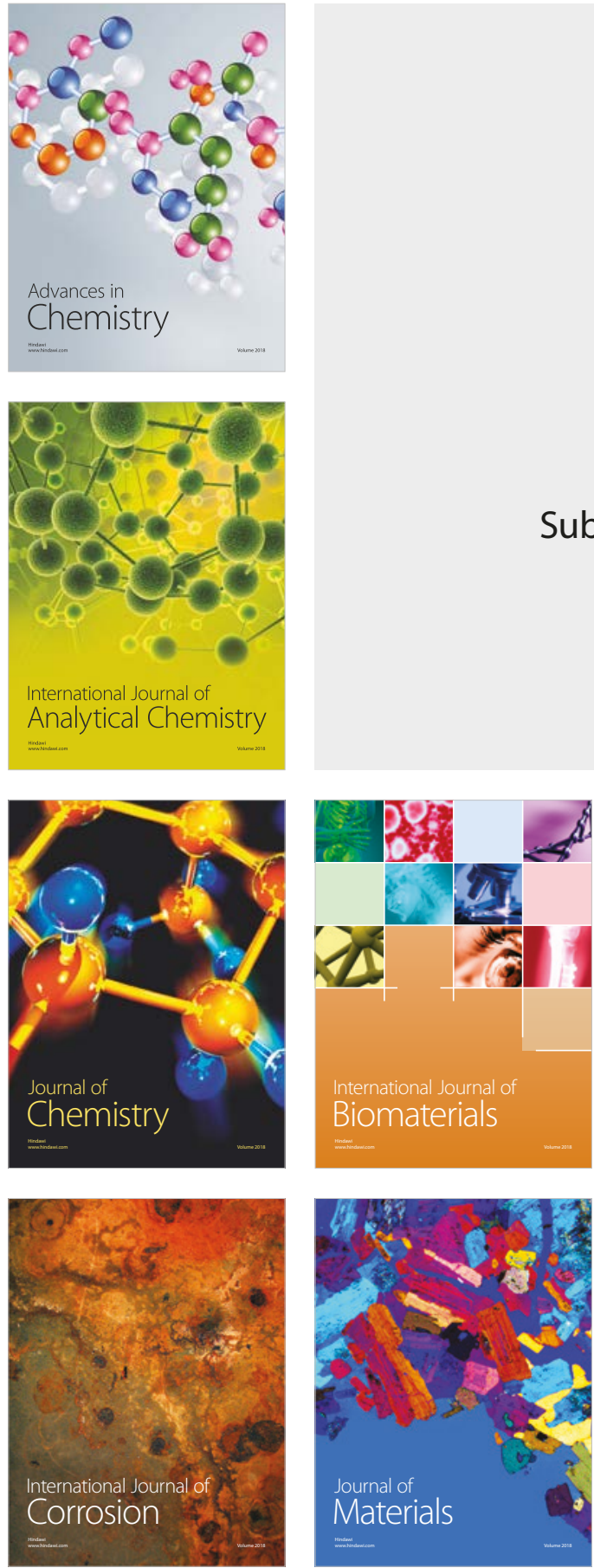

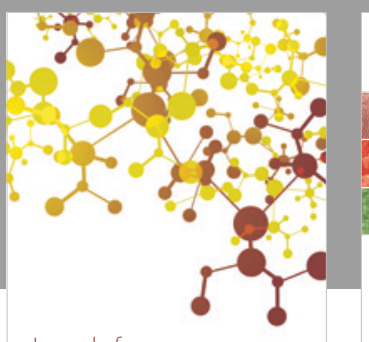

Journal of

Applied Chemistry
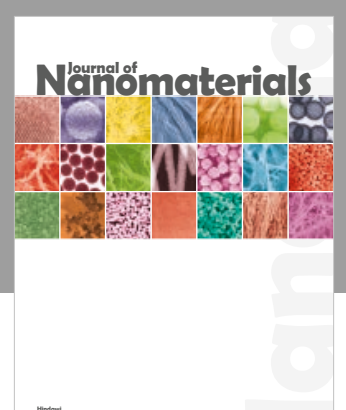

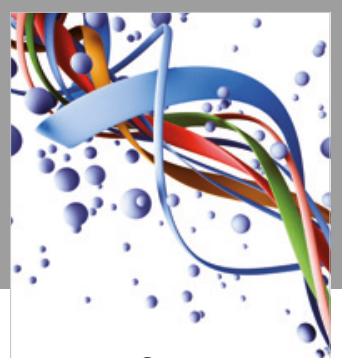

Scientifica

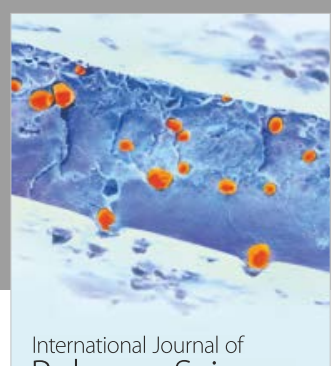

Polymer Science

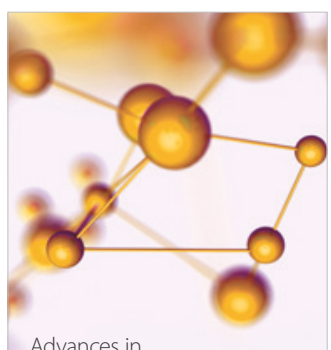

Physical Chemistry
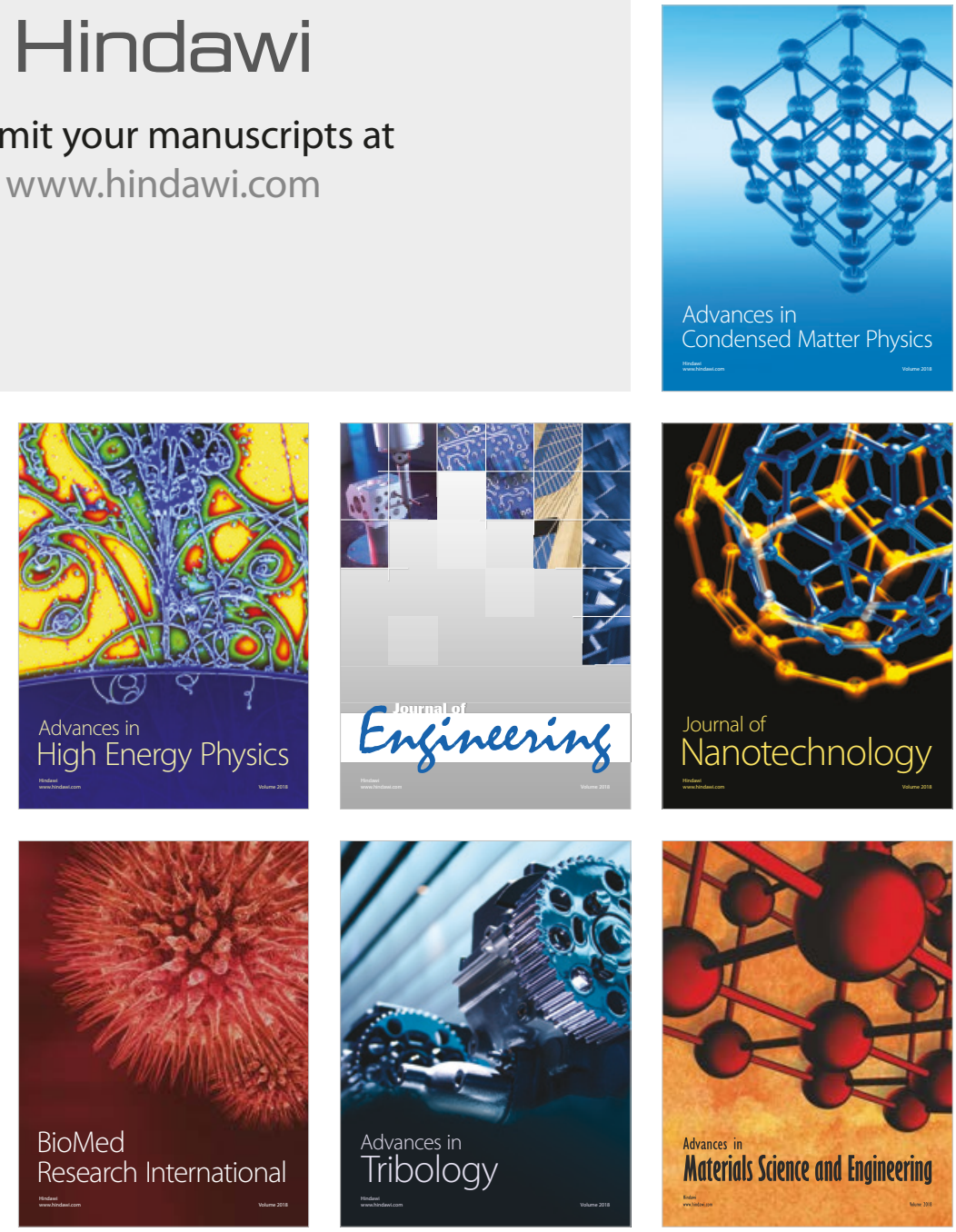